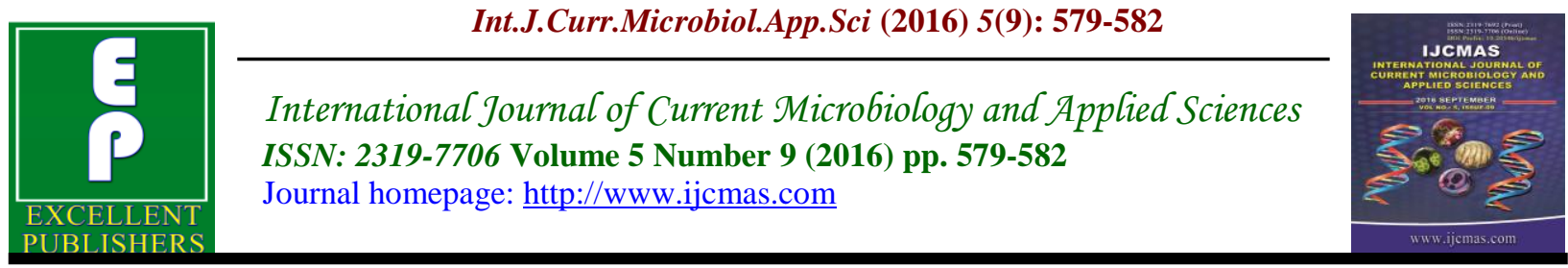

Case Study

http://dx.doi.org/10.20546/ijcmas.2016.509.065

\title{
Molluscum contagiosum Infection - A Case Report
}

\author{
Venkata Hemalatha Neeli and Perala Bala Murali Krishna*
}

Department of Microbiology, Andhra Medical College, Visakhapatnam, India

*Corresponding author

\section{A B S T R A C T}

Keywords

Molluscum contagiosum, molluscum bodies.

\section{Article Info}

Accepted:

20 August 2016

Available Online:

10 September 2016
Molluscum contagiosum is a common childhood viral infection of squamous epithelium of the skin appearing as pearly-white, dome-shaped umbilicated papules. Acquisition of the virus follows contact with infected persons or contaminated objects and sources such as swimming pools. It is observed with a higher frequency in tropical climates. Molluscum contagiosum virus cannot be propagated in vitro. Therefore the cases are mostly diagnosed clinically and the diagnosis is confirmed by the demonstration of characteristic molluscum bodies from the lesions.

\section{Introduction}

Molluscum contagiosum is a common skin disease of viral origin, caused by Molluscum contagiosum (MC) virus, a human pox virus (Mohan et al., 2013). It is a double stranded DNA virus. It has traditionally been regarded as a paediatric disease (ShefaliSinghal et al., 2013; Soorya et al., 2006; Koning et al., 1994).

Molluscum contagiosum infection is transmitted directly by skin-to-skin contact and indirectly bysharing of fomites (ShefaliSinghal et al., 2013). Swimming pool usage, living in close proximity and residence in tropical climates aresome of the factors associated with higher rates of infection (Soorya et al., 2016).
Incubation period is about 2-7 weeks. Molluscum contagiosum is a benign selflimiting disease that manifests as pearlywhite umbilicated nodules of about $2-5 \mathrm{~mm}$ in diameter.

\section{Case History}

A 5yr old female child was brought to the dermatology OPD with multiple, domeshaped, pearly-white umbilicated lesions on the posterior aspect of left thigh (Figure 1). A clinical diagnosis of Molluscum contagiosum was made. Under strict aseptic conditions, the lesions were extirpated; the sample thus obtained was crushed between two slides and was sent for histopathology to confirm the clinical diagnosis. 
The crushed smear was then fixed in methanol. After fixation, smears were stained with Haematoxylin and Eosin, Papanicolaou and May-Grunwald Giemsa stains. Characteristic molluscum bodies, also known as Henderson Patterson bodies were demonstrated by all the three staining techniques (Figures 2, $3 \& 4$ ).

Under high-power magnification, they appeared as ovoid, deeply staining bodies with a hyaline, homogenous structure surrounded by a membrane.

\section{Results and Discussion}

Molluscum bodies are the largest known inclusion bodies measuring about 30-35 microns in diameter. They are virus transformed keratinocytes composed of large numbers of virus particles embedded in a protein matrix.

Fig.1 Pearly white umbilicated lesions

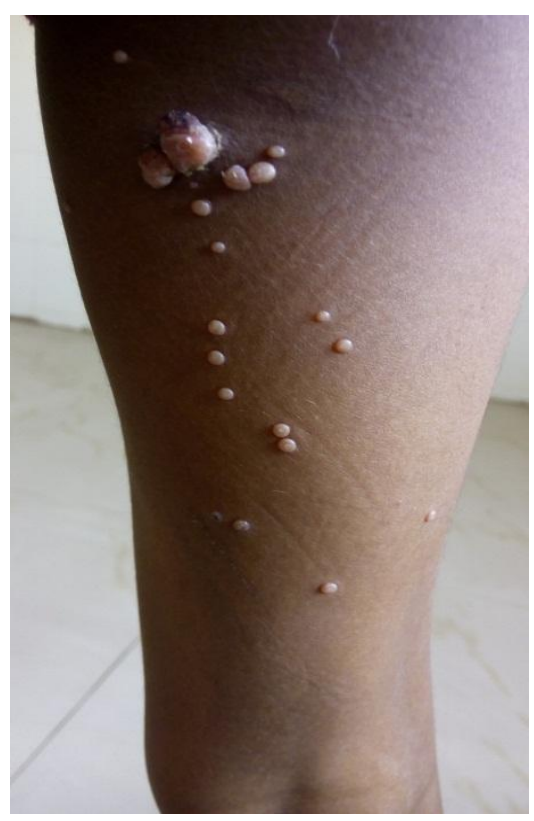

Fig.2 Haematoxylin\& eosin staining demonstrating the characteristic molluscum bodies (40X)

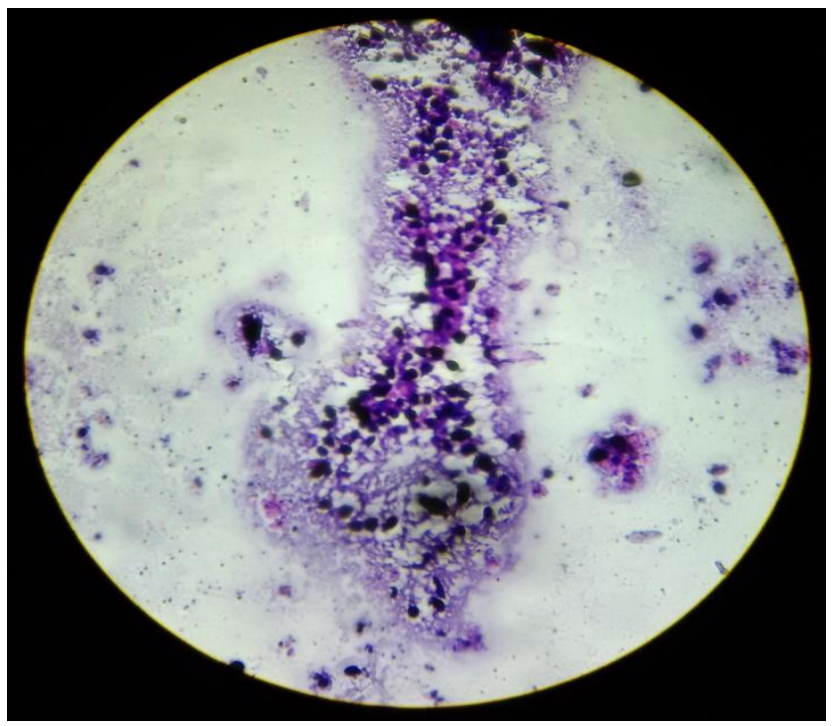


Fig.3 Papanicolau staining demonstrating the characteristic molluscum bodies (40X)

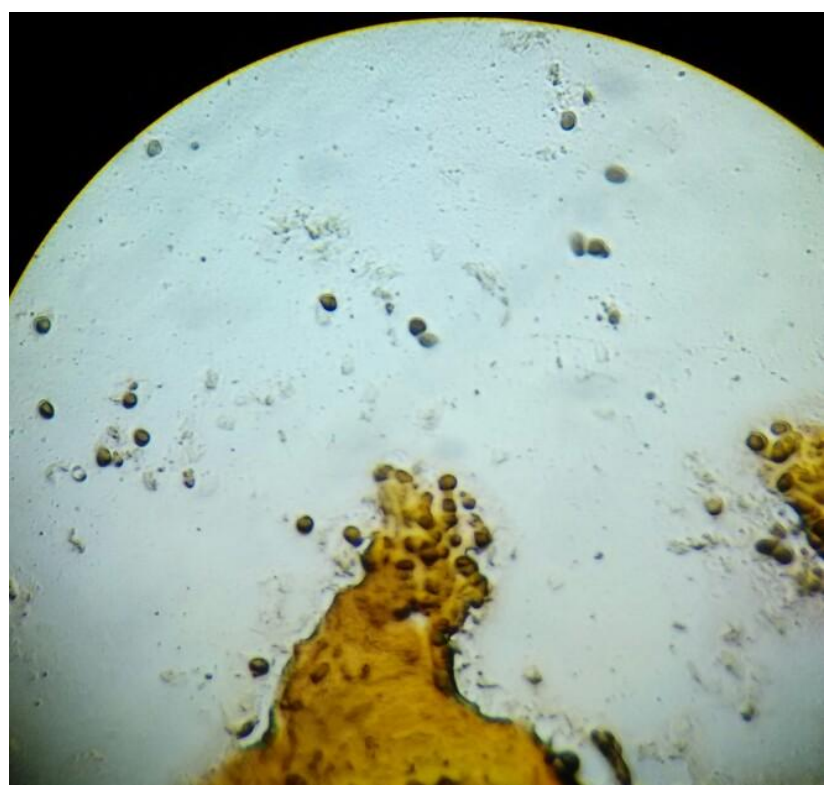

Fig.4 May-Grunwald Giemsa staining demonstrating the characteristic molluscum bodies (40X)

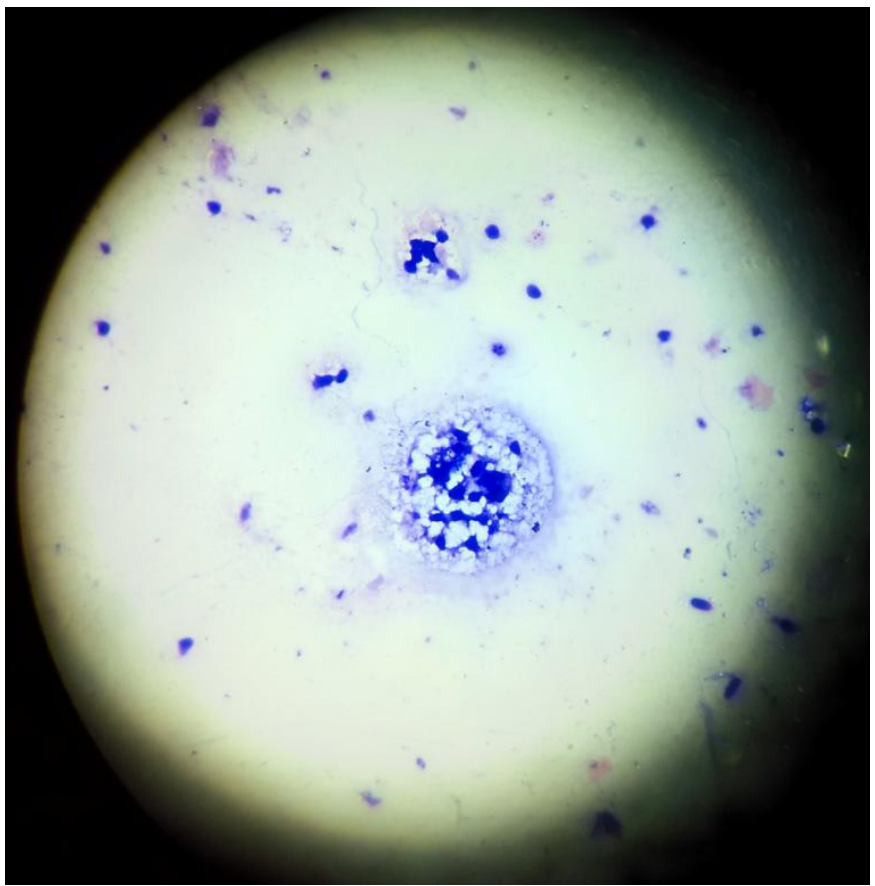

In conclusion, Molluscum contagiosum virus cannot be propagated in vitro. The cases are mostly diagnosed clinically and the diagnosis is confirmed by the demonstration of characteristic molluscum bodies from the lesions.

\section{References}

Koning, S., M.A. Bruijnzeels, L.W.A. Van Suijlekom-Smit, J.C. 1994. Van Der Wouden. Molluscum contagiosum in 
Dutch general practice. British $J$. General Practice, 44: 417-419.

Mohan, R.P., Verma, S., Singh, A.K. and Singh, U. 2013. Molluscum contagiosum: report of one case with overview. BMJ Case Rep., 17.

Shefali Singhal, Archana, S., Shilpa Reddy, Murugnantham, T.V. and Hamedullah, A. 2013. A Case Report of Molluscum
Contagiosum Infection in an HIV Infected Individual. Int. J. Med. Res. Health Sci., 2(3): 712-715.

Soorya, B.B., Jayakar Thomas, Manoharan, D., Manoharan, K. and Sukanya, G. 2016. Disseminated Molluscum Contagiosum in a HIV Positive Child a Case Report. Int. J. Adv. Case Reports, 3(3): 153-154.

\section{How to cite this article:}

Venkata Hemalatha Neeli and Perala Bala Murali Krishna. 2016. Molluscum contagiosum Infection - A Case Report. Int.J.Curr.Microbiol.App.Sci. 5(9): 579-582. doi: http://dx.doi.org/10.20546/ijcmas.2016.509.065 